\title{
Temporal stability of soil moisture on two transects in a desert area of northwestern China
}

\author{
Pingping Zhang' ${ }^{1}$ Ming'an Shao ${ }^{1,2} \cdot$ Xingchang Zhang ${ }^{1}$
}

Received: 19 August 2014 / Accepted: 10 August 2015/Published online: 6 January 2016

(C) Springer-Verlag Berlin Heidelberg 2015

\begin{abstract}
Temporal stability of soil moisture has important implications for optimal and effective field monitoring and has been observed for a range of soil and landscape conditions. However, relatively less is known about temporal stability of soil moisture in desert areas. In this study, two 5-km transects (TranA and TranB) with different soil properties in a desert area of northwestern China were chosen to assess the characteristics of the temporal variability and stability of soil moisture, to identify representative sampling locations (RSLs), and to evaluate the effect of sampling frequency on the determination of temporal stability. For each transect, moisture contents of the surface soil were measured using Theta Probes on 35 occasions at 51 locations from April to October 2012. The results showed that soil moisture for the finer-textured TranA was consistently higher and more variable than for the coarsertextured TranB. Both transects exhibited strong temporal stability during the monitoring period. Locations with higher sand contents tended to have more pronounced temporal stabilities. The RSL identified in each transect accurately represented the mean moisture contents of the transects over time, with coefficients of determination $\left(R^{2}\right)$
\end{abstract}

Ming'an Shao

mashao@ms.iswc.ac.cn

Pingping Zhang

zhangping200573@126.com

1 State Key Laboratory of Soil Erosion and Dryland Farming on the Loess Plateau, Institute of Soil and Water

Conservation, Chinese Academy of Sciences and Ministry of Water Resources, Yangling 712100, China

2 Key Laboratory of Ecosystem Network Observation and Modeling, Institute of Geographical Science and Natural Resources, Chinese Academy of Sciences, Beijing 100101, China higher than 0.95 and root mean square errors lower than $1 \% \mathrm{vol} / \mathrm{vol}$. Soil moisture has significantly higher degrees of temporal stability during dry periods than during wet periods. The effect of sampling frequency on temporal stability of soil moisture was not as evident, particularly for the coarser-textured soil. This study provides insights for designing strategies for the sampling and monitoring of soil moisture in the hydrological applications in desert areas.

Keywords Soil moisture - Desert hydrology - Temporal stability · Dry and wet period - Sampling frequency . Transect

\section{Introduction}

Soil moisture is broadly recognised as a dominant factor in many hydrological, ecological, and environmental processes (Grayson and Western 1998; Western and Blöschl 1999; Brocca et al. 2009; Hu et al. 2010b; Gao and Shao 2012b; Penna et al. 2013). It is also the principal limiting factor in desert regions for the growth of vegetation, for permanently controlling desertification (Berndtsson et al. 1996), and for the organisation and function of ecosystems (Rodriguez-Iturbe et al. 1999). Knowledge of the status of soil moisture and its spatial distribution has important implications for hydrologic, agricultural, and climatic modelling and prediction (Brocca et al. 2012). For these reasons, a major recent concern has been the accurate and reliable estimation of mean soil moisture content at different scales (Grayson and Western 1998; Brocca et al. 2009, 2010; Hu et al. 2010a; Biswas and Si 2011; Gao and Shao 2012a; Jia et al. 2013a, b).

Soil moisture content, however, has long been acknowledged as highly variable in space and time. The 
high variability of soil moisture therefore necessitates a large number of sampling locations for a complete description of its spatiotemporal patterns and for accurately estimating the mean. To reduce costs, approaches that can optimise the in situ sampling locations without losing information have become increasingly important (Brocca et al. 2009). Vachaud et al. (1985) introduced the idea that areas could maintain spatial patterns of soil moisture over time, and attention has since been focused on evaluating the temporal stability of soil moisture. Despite the large variability of soil moisture, some locations within an area often consistently exhibit moisture contents and temporal fluctuations similar to the mean moisture content of the study area. These similarities are useful, because once these locations are identified, an area's mean moisture content can be estimated from a small number of sampling locations while maintaining a high accuracy of estimation (Vachaud et al. 1985).

The temporal stability of soil moisture content has been observed throughout a wide range of landscapes and terrains, e.g. grasslands (Vachaud et al. 1985; Schneider et al. 2008; Brocca et al. 2009; Zhao et al. 2010), croplands (da Silva et al. 2001; Cosh et al. 2004; Jacobs et al. 2004; Heathman et al. 2012), forests (Lin 2006), gullies (Gao et al. 2013), and mountains (Grant et al. 2004; Guber et al. 2008; Vivoni et al. 2008; Williams et al. 2009). Temporally unstable spatial patterns, however, were reported in a cultivated Vesuvian soil (Comegna and Basile 1994). Kamgar et al. (1993) found that the temporally stable pattern of soil moisture was linked to sampling depth, and surface sampling locations did not display temporal persistence. These disparate findings suggest site specificity. More studies in different environments are needed to confirm the general applicability of the concept of temporal stability to different regions. With the exception of the study by Pan et al. (2009), the concept of temporal stability has not been applied to desert areas, due to the difficulties and associated costs of sampling soil moisture. As far as we know, no studies have assessed the presence of representative sampling locations (RSLs) at the scale of long transects in desert areas. In fact, the temporal stability of soil moisture in desert areas should differ from that of previous studies because of the low soil moistures and the seasonality of precipitation. The study of temporal stability of soil moisture for desert areas can be of great interest for the design of sampling schemes and the development of predictive models for monitoring soil moisture ( $\mathrm{Hu}$ et al. 2010a).

Soil texture can influence hydraulic properties and the ability of soil to retain water and can hence have a particularly significant effect on the distribution pattern of soil moisture. Currently, soil texture has been commonly implicated in the existence and extent of temporal stability of soil moisture (Vachaud et al. 1985; da Silva et al. 2001; $\mathrm{Hu}$ et al. 2010a; Biswas and Si 2011; Jia et al. 2013a). Jacobs et al. (2004) found that the most temporally stable locations were associated with moderate to moderately high clay contents, but Mohanty and Skaggs (2001) found that sandy loam fields had a more pronounced temporal stability than did silty loam fields. A consistent conclusion for the effect of soil texture on temporal stability cannot thus be drawn at present. Moreover, other factors such as soil depth, vegetation, topography, spatial scale, temporal scale (including sampling frequency and duration of the observation period), and soil wetness can also influence the temporal stability of soil moisture [see the review by Vanderlinden et al. (2012) for comprehensive references].

Our study focused mainly on the influence of soil wetness and sampling frequency. The influence of soil wetness on the temporal stability of soil moisture is still very controversial. Zhao et al. (2010) found that the spatial patterns of soil moisture in plots in a semi-arid steppe were more stable over time during wet seasons and less stable during dry or transitional periods. Similar results have also been reported from other regions (Kachanoski and Jong 1988; Gómez-Plaza et al. 2000; Hupet and Vanclooster 2002; Williams et al. 2009; Zhao et al. 2010; Zhao et al. 2013). Gómez-Plaza et al. (2000) ascribed the lower temporal stability during dry periods to the high water demand of vegetation. In contrast, Martínez-Fernández and Ceballos (2003) used 3 years as a training period and found that temporal stability decreased during the recharge periods and was more pronounced during dry conditions in a semi-arid area with a continental Mediterranean climate in Spain. Penna et al. (2013), however, did not find a consistent trend of temporal stability during dry or wet periods. More studies with a variety of soils, terrains, and climatic conditions and over a wide range of scales are thus needed to determine the effect of wet and dry conditions on the temporal persistence of soil moisture.

The frequency of sampling for determining RSLs has pragmatic implications. Finding RSLs would considerably reduce the effort and cost of sampling. The effect of sampling frequency on the determination of temporal stability of soil moisture, however, has received little attention. Brocca et al. (2010) found that identifying RSLs was closely dependent on sampling frequency; RSLs were correctly identified in $90 \%$ of cases at a sampling frequency of 12 (a total of 35 sampling occasions for the entire data set). Guber et al. (2008) and Zhao et al. (2013), however, found that the RSLs based on temporal stability were insensitive to sampling frequency.

To gain a deeper insight into these questions and with the goal of reducing the number of soil moisture samplings, we measured soil moisture along two transects over 35 
occasions from April to October 2012. The specific objectives of the study were to: (1) compare the characteristics of temporal variability and stability along two intersecting desert transects with different soil properties; (2) identify the RSLs that could accurately estimate the mean moisture contents of the transects; (3) evaluate the temporal stability of soil moisture for wet and dry periods, and (4) investigate the effect of sampling frequency on the temporal stability of soil moisture.

\section{Materials and methods}

\section{Study area}

The study was conducted on two transects (TranA and TranB) of a desert area in the central region of the Heihe River Basin in Gansu Province of northwestern China (Fig. 1). The area is very flat, with some undulating denuded terrain with sand dunes. The vegetational cover is 5-15\%, and its distribution is discontinuous (5-15\%) and can be described as patches of plants surrounded by bare areas. The main plant species are sub-shrubs, including Reaumuria soongorica (Pall.) Maxim. and Nitraria sphaerocarpa Maxim., and a few annual desert species such as Suaeda microphylla (Mey.) Pall. and Halogeton arachnoideus Moq. The area has an arid desert climate, with dry and hot summers, cold winters, low rainfall, and high evaporation. The mean annual precipitation is $117 \mathrm{~mm}$, and the mean air temperature is $7.6^{\circ} \mathrm{C}$. Brief summer (July-September) showers contribute $65 \%$ of the total annual precipitation. The mean annual pan evaporation of approximately $2390 \mathrm{~mm}$ is 20 times greater than the annual precipitation. The average annual wind speed is $3.2 \mathrm{~m} \mathrm{~s}^{-1}$. The wind is mainly from the northwest, and the dominant windy days and wind storms occur between March and May. The zonal soil is derived from diluvial to alluvial materials and is classified as gray-brown desert soil. The soil is particularly susceptible to wind erosion due to its coarse texture and low concentration of nutrients. The aeolian transport of fine material enables the area to present varying thicknesses of fine deposits in the surface layer and thus a considerable spatial heterogeneity of soil texture, ranging from sand to clay.

Both transects, perpendicular to one another, are $5 \mathrm{~km}$ in length and are bordered by a young oasis to the southwest, a remnant of the Qilian Mountains to the north, and an extension of the Badain Jaran Desert to the southeast (Fig. 1c). TranA is closer to the oasis, and TranB is closer to the mountains. Because of the Aeolian erosion caused by the perennial northwest wind, the two transects have different soil properties, with TranA having a finer soil texture than TranB. A detailed list of the soil properties based on the soil samples collected from each transect is given in Table 1. Note that topographic and vegetational properties were not included in this study, because the topography is very flat and the vegetation is very sparse in this area.

\section{Soil sampling and data collection}

Each transect had 51 sample sites approximately $100 \mathrm{~m}$ apart. Soil moisture in the surface soil layer $(0-6 \mathrm{~cm})$ was generally measured weekly from 15 April to 15 October 2012 (a total of 27 sampling campaigns) using a Theta Probe (Type ML2x, Delta-T Devices, Cambridge, UK). Soil moisture was also measured after a heavy rain on eight occasions, for a total of 35 sampling campaigns. We averaged three replicate measurements for each location and date to reduce the influence of possible micro-scale variability. Soil moisture contents $(u, g / g)$ of the surface layer $(0-6 \mathrm{~cm})$ were also determined gravimetrically at each location for calibrating the Theta Probe. These calibrations were performed three times during the measurement period (May, August, and October) for testing a range of soil wetness. Undisturbed soil core samples $\left(100 \mathrm{~cm}^{3}\right)$ were also collected from the $0.5-5.5 \mathrm{~cm}$ soil layer to determine soil bulk density $\left(\mathrm{BD}, \mathrm{g} / \mathrm{cm}^{3}\right)$ for transforming the values of $\mathrm{u}$ to their corresponding volumetric moisture contents $(\theta, \mathrm{vol} / \mathrm{vol})$. The instrument-derived moisture values $\left(X, \mathrm{~cm}^{3} / \mathrm{cm}^{3}\right)$ were then plotted against the volumetric moisture contents $(Y, \mathrm{vol} / \mathrm{vol})$ to obtain linear calibration curves:

$Y=0.5295 X+0.0755\left(R^{2}=0.89\right.$, RMSE $\left.=0.90 \%\right)$

$R^{2}$ is the coefficient of determination, and RMSE is the root mean square error.

\section{Data analysis}

The temporal stability of soil moisture content was assessed by relative difference analyses. Following Vachaud et al. (1985), the relative difference for the individual measurement of soil moisture at location $i$ on sampling occasion $j$ with respect to the spatial mean soil moisture content $\overline{\theta_{j}}$ is:

$\delta_{i j}=\frac{\theta_{i j}-\overline{\theta_{j}}}{\overline{\theta_{j}}}$.

The temporal mean relative difference (MRD) and its standard deviation (SDRD) over the sampling period are:

$\overline{\delta_{i}}=\frac{1}{M} \sum_{j=1}^{M} \delta_{i j}$ 


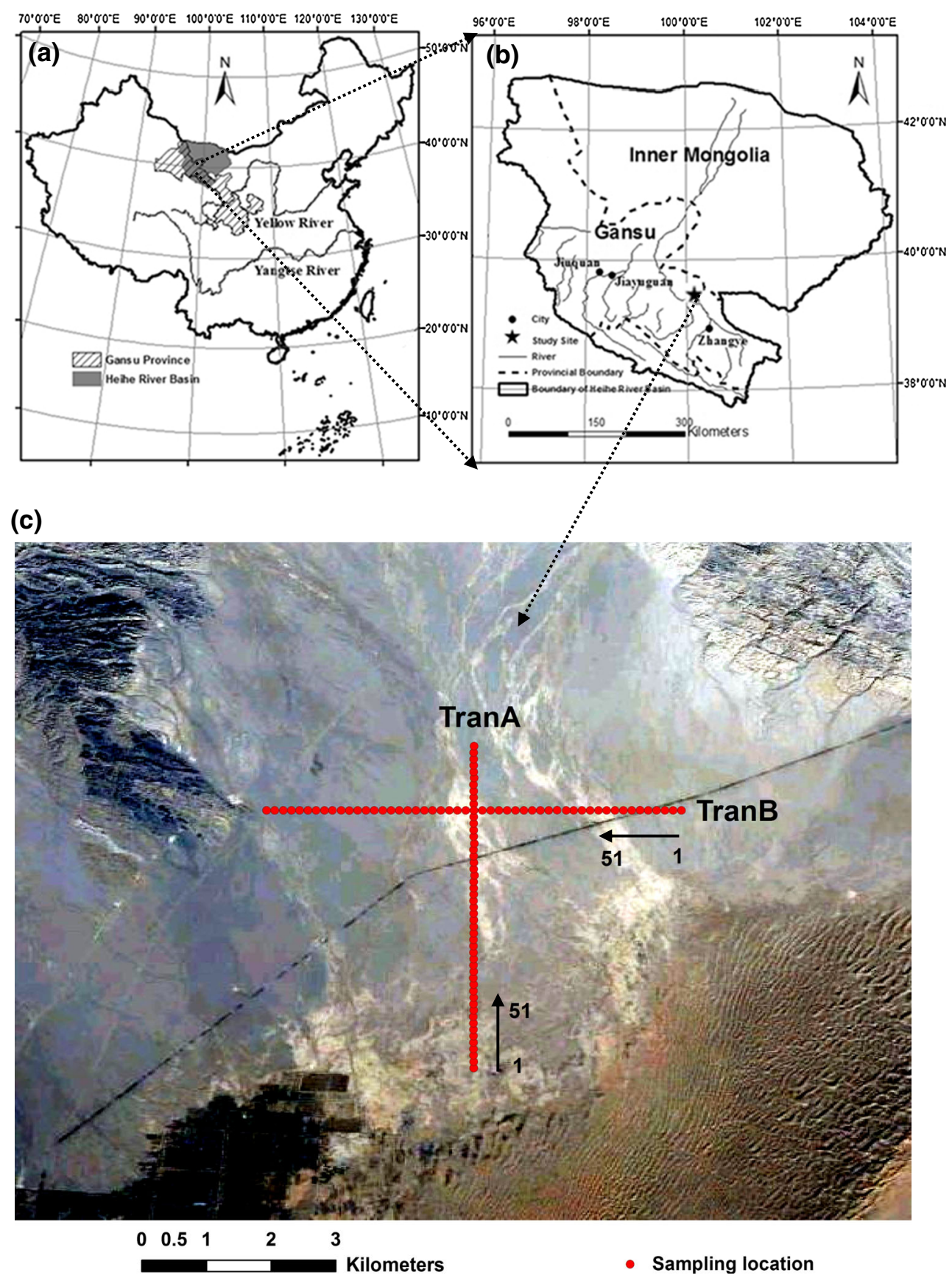

Fig. 1 a The location of Gansu Province and the Heihe River Basin, China, b the location of the study site in the Heihe River Basin, and $\mathbf{c}$ the soil sampling locations in the study area

and

$\sigma\left(\delta_{i}\right)=\sqrt{\frac{1}{M-1} \sum_{j=1}^{M}\left(\delta_{i j}-\overline{\delta_{i}}\right)^{2}}$,

where $M$ represents the total number of sampling occasions. Positive and negative MRD values indicate soil that is wetter and drier, respectively, than the spatial mean soil moisture. SDRD characterises the variability of MRD at a location within the experimental period, i.e. SDRD is an indicator of temporal stability.

An index of temporal stability (ITS, Zhao et al. 2010) that includes both MRD and SDRD was computed to provide a single indicator of the most temporally stable location and, at the same time, of the location most representative of the mean soil moisture of the transect: 
Table 1 Selected physical and chemical properties of the surface $(0-6 \mathrm{~cm})$ soil for TranA and TranB

\begin{tabular}{|c|c|c|c|c|c|c|}
\hline \multirow[t]{2}{*}{ Variables } & \multicolumn{3}{|l|}{ TranA } & \multicolumn{3}{|l|}{ TranB } \\
\hline & Mean & SD & $\mathrm{CV}(\%)$ & Mean & SD & $\mathrm{CV}(\%)$ \\
\hline Sand $(\%)$ & 71.8 & 21.8 & 30.4 & 84.6 & 6.5 & 7.7 \\
\hline Silt (\%) & 12.7 & 9.7 & 76.0 & 6.7 & 3.0 & 44.9 \\
\hline Clay (\%) & 15.4 & 12.9 & 83.8 & 8.8 & 3.7 & 41.7 \\
\hline $\mathrm{BD}\left(\mathrm{kg} / \mathrm{m}^{3}\right)$ & 1547 & 138.9 & 9.0 & 1640 & 128.0 & 7.8 \\
\hline $\mathrm{Ks}\left(10^{-5} \mathrm{~m} / \mathrm{s}\right)$ & 0.6 & 0.7 & 125.1 & 0.4 & 0.3 & 74.4 \\
\hline $\mathrm{TP}(\%)$ & 40.9 & 4.1 & 10.0 & 40.2 & 4.8 & 12.1 \\
\hline SOC $(\mathrm{g} / \mathrm{kg})$ & 1.7 & 0.7 & 42.0 & 1.5 & 0.4 & 24.4 \\
\hline
\end{tabular}

$B D$ bulk density, $K_{S}$ soil saturated hydraulic conductivity, $T P$ total porosity, $S O C$ soil organic carbon content, $S D$ standard deviation, $C V$ coefficient of variation (Gajem et al. 1981; Schaap et al. 1998)

$\operatorname{ITS}_{i}=\sqrt{\left({\overline{\delta_{i}}}^{2}+\sigma\left(\delta_{i}\right)^{2}\right)}$

The location with the lowest ITS has the highest temporal stability.

$R^{2}$ and RMSE were calculated as measures of the goodness-of-fit between observed and estimated mean moisture contents along a transect. Paired-samples $t$ tests and independent-samples $t$ tests tested for differences of soil moisture content and variability and of temporal stability of soil moisture between the two transects. The paired-samples $t$ tests also evaluated the influence of soil wetness and sampling frequency on the temporal stability of soil moisture. The statistical analyses of the soil moisture data used SPSS 16.0 software.

\section{Results and discussion}

\section{Temporal and spatial analysis of soil moisture}

The temporal evolution of mean moisture content along both transects are shown in Fig. 2a with the corresponding daily precipitation. The two transects generally displayed comparable temporal dynamics. As expected, soil moisture responded markedly to precipitation, increasing rapidly after a significant rain and decreasing slowly during dry periods. The responses, however, showed apparent seasonal trends. The increase in mean moisture content after a rain was larger in summer than in spring and autumn, mainly due to the greater depth of precipitation in summer. As shown in Fig. 2b, c, the standard deviation (SD) and coefficient of variation $(\mathrm{CV})$ of the soil moisture followed the same trend as the mean, having larger values in summer. The experimental period was divided into two categories based on the different conditions of soil wetness and the characteristics of spatial variability of soil moisture (i.e. SD and CV): a wet period from 5 June to 2 September and dry periods from 16 April to 4 June and 3 September to 15 October (Fig. 2).

Even though the two transects intersected each other, they differed in both mean soil moisture and spatial variability (Fig. 2). TranA was consistently wetter than TranB $(p<0.01)$, which was likely due to the slight differences in the soil properties of the two transects (Table 1). The soil along TranA had a much finer texture, which would tend to improve soil structure and increase the capacity to retain moisture against the upward loss from evaporation or the downward loss from infiltration. Since the influence of soil texture on soil moisture can be very important following rains (Famiglietti et al. 1998), the differences in soil moisture content between the transects became increasingly pronounced during the wet period (Fig. 2a). Significantly higher spatial variability of soil moisture was also found on TranA $(p<0.01)$. This result contradicts the findings of Brocca et al. (2007), Choi and Jacobs (2007), and Brocca et al. (2009) who observed increasing spatial variability of soil moisture as the sand content increased. This disagreement with our findings may be ascribed to the wide range of soil textures from clay to sand and the scattered distribution in this area that may have introduced spatial variability of soil moisture.

Figure 3 shows the relationship between the SD and the mean of soil moisture for both transects. A clear positive correlation $(p<0.01)$ between the two variables can be recognised, demonstrating that the variability of soil moisture increased with mean soil moisture. That is, soil moisture was more heterogeneously distributed in this area under wetter than under drier conditions. The results are consistent with previous studies (Western et al. 1999; Martínez-Fernández and Ceballos 2003). Meyles et al. (2003), Brocca et al. (2007) and Penna et al. (2013), however, found negative relationships between the SD and mean. Penna et al. (2009) even observed that the SD peaked in the mid-range of soil moisture (23-29\%) and then decreased independent of further soil drying or wetting. Different statuses of soil moisture may be one important reason for these differences. According to Peters-Lidard and Pan (2002), the SD increases with drying if soil moisture is between saturation and field capacity of the soil, but decreases with drying if soil moisture is lower than field capacity of the soil. As soil dries, starting from saturation, some patches that characterised by fine texture can still remain wet, leading to enhanced spatial variability (Hills and Reynolds 1969). But when it dries beyond the field capacity of the soil, the remaining wet patches may gradually lose water via strong evaporation, resulting in 
Fig. 2 Time series of a daily precipitation $(\mathrm{mm})$ and mean soil moisture content (vol/vol), b standard deviation ( $\mathrm{vol} / \mathrm{vol})$, and $\mathbf{c}$ coefficient of variation (\%) for the surface $(0-6 \mathrm{~cm})$ soil layers of TranA and TranB

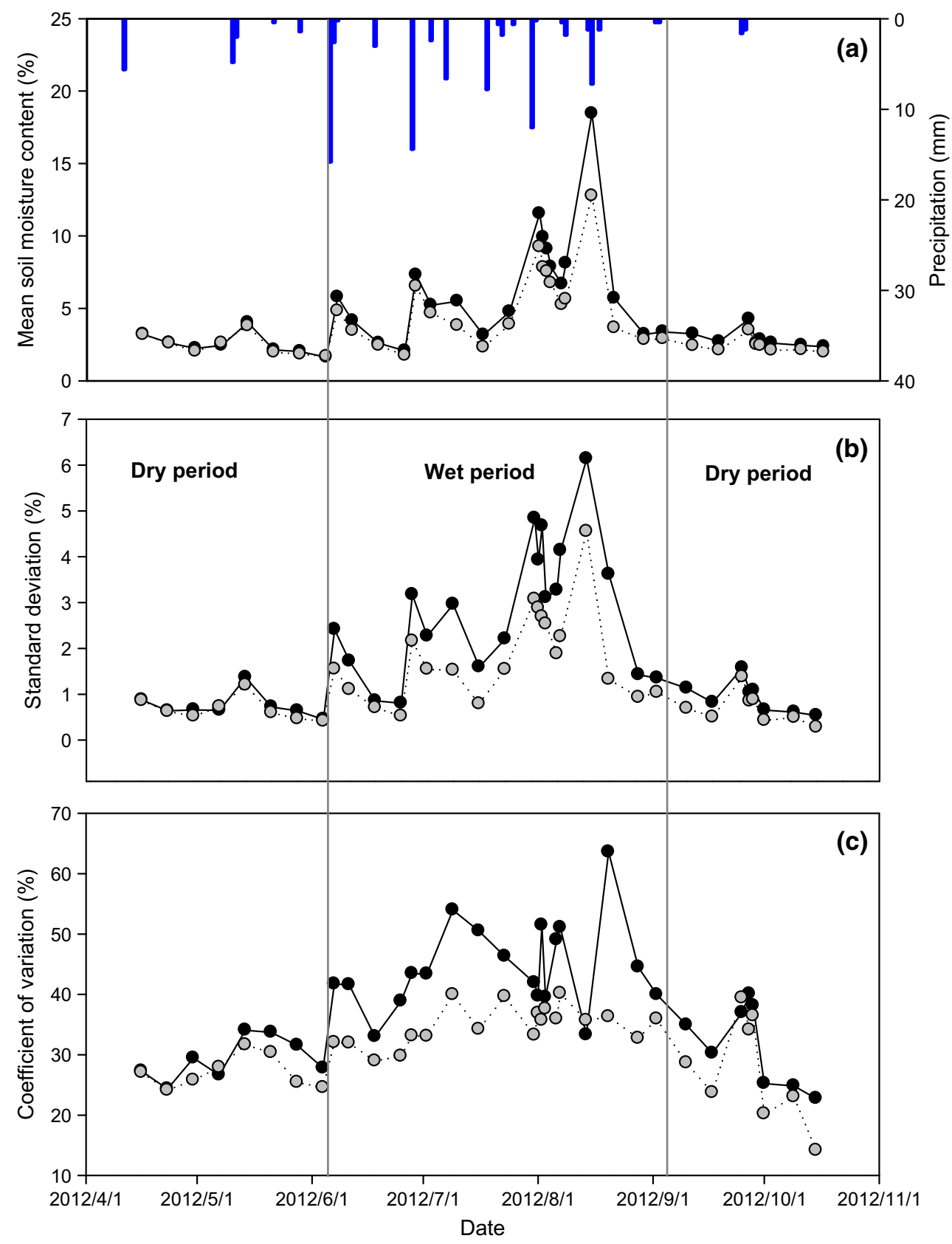

decreased spatial variability. The positive relationship between the SD and mean of soil moisture in this study is thus probably due to the dry conditions of the soil as a result of the low precipitation and high evaporation in this area.

As shown in Fig. 3, the relationship between SD and mean moisture content can be well described by logarithmic laws, with $R^{2}$ as high as 0.93 . With an understanding of these laws, quantifying the number of samplings required to determine the mean moisture contents of the transects at given confidence levels and relative errors is possible, but doing so is beyond the scope of this paper.

\section{Temporal stability of soil moisture for the entire study period}

Figure 4 shows the ranked MRDs of soil moisture contents and associated SDRDs for the two transects over the entire experimental period. Note that location 15 on TranA and location 20 on TranB are not shown because they exhibited particularly higher values of MRD and SDRD than the other locations along the transects. The higher MRDs for these two locations are due to their location in erosion ditches that can sometimes be flooded after rains and can thus have soil moisture contents higher 


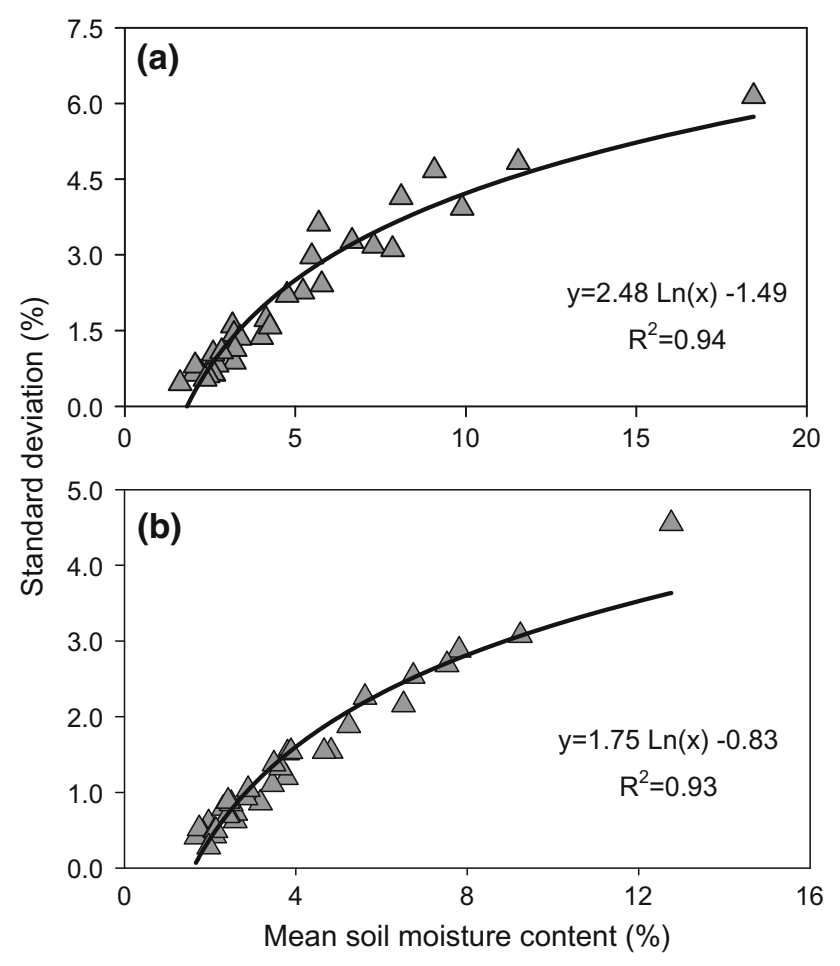

Fig. 3 Relationships between standard deviation (vol/vol) and mean soil moisture content (vol/vol) for a TranA and b TranB

than the other locations. MRDs ranged from -40.6 to $61.62 \%$ and from -34.0 to $38.4 \%$ for TranA and TranB, respectively. TranA had a larger range of MRDs than did TranB, which reflected the stronger spatial variability of soil moisture for TranA, as indicated by the higher values of SD and CV in Fig. 2. The mean value of MRD for the set of locations lacked symmetry, with 32 and 28 of the locations systematically below the mean MRD and 18 and 22 above it for TranA and TranB, respectively. Similar asymmetric characteristics of MRD have also been reported from other regions (Martínez-Fernández and Ceballos 2003; Cosh et al. 2008). The observed ranges of MRD in our study were larger than those of Jia and Shao (2013) $(<27 \%)$, who also conducted measurements along transects but at a much smaller scale $(61 \mathrm{~m})$. These differences confirm the conclusions of Mohanty and Skaggs (2001), Schneider et al. (2008), and Brocca et al. (2009) that the range of MRD would widen with the scale of measurement because of the higher expected diversities and complexities of the soil, topography, and vegetation. Gómez-Plaza et al. (2000), however, observed similar or larger ranges of MRD (110-120\%) as ours along three small transects (200-310 m). This disagreement may be partly due to the differences in the landscapes, topographies, sampling schemes, measurement techniques, and periods of monitoring (Zhao et al. 2010; Vanderlinden et al. 2012).
The two differently textured transects had similar SDRDs $(p>0.05)$ (Fig. 4), indicating that temporal stability on the scale of the transect was not affected by soil texture. On the scale of the location, though, drier soil tended to have a higher temporal stability, i.e. locations with negative MRDs. The drier locations at our study site always had high sand contents. Soil moisture content may thus be more temporally stable in coarse-textured soil, which is consistent with the findings of Mohanty and Skaggs (2001), Martínez-Fernández and Ceballos (2003), and $\mathrm{Hu}$ et al. (2010a). Martínez-Fernández and Ceballos (2003) ascribed this association to the inability of the soils to retain water because of the predominance of a sandy fraction. Jacobs et al. (2004), however, reported different results; sampling locations with moderate to moderately high clay contents tended to have more pronounced temporal stabilities.

The identification of a single sampling location that best represents the mean soil moisture of the field or transect of interest is an important aspect of the concept of temporal stability. As far as we know, no studies have evaluated the existence of an RSL on a large-scaled transect in a desert area. Based on the definition of Vachaud et al. (1985), an RSL should be reliable and representative, having an MRD equal or closest to zero and being associated with the lowest SDRD, i.e. having the lowest value of ITS (Zhao et al. 2010). We thus calculated the ITS values for all sampling locations along the two transects (Fig. 4). The ITS generally had the same magnitude and trend as the MRD, because the MRD component of Eq. 5 plays a more important role in calculating ITS, while SDRD changes very little at different locations. The mean value of ITS, unlike SDRD, tended to be much higher for TranA $(34.9 \%)$ than for TranB $(29.5 \%)$, although the differences were not statistically significant $(p>0.05)$. The topographies and vegetation of the two transects were comparable, so we ascribed this slight difference in the ITS to the differences in soil properties (Table 1). Penna et al. (2013) indicated that relatively homogeneous soils favour temporal persistence in the patterns of soil moisture. The more heterogeneous characteristics of TranA, though, led to inconsistent patterns of changes in the status of soil water and thus to a lower temporal stability. Locations 11 (ITS $=13.3 \%)$ and 31 (ITS $=12.0 \%)$ on TranA and TranB, respectively, had the lowest ITS values and can thus be considered as the best RSLs. To test the ability of these locations to accurately represent the entire transects, the soil moistures at the RSLs were plotted against the mean soil moistures of the transects (Fig. 5). With a few exceptions, these two RSLs estimated the mean soil moistures within $2 \%$ on each sampling day. The linear regression analyses indicated that these RSLs were both well associated with the transect mean and provided 
Fig. 4 Rank ordered mean relative difference (\%) of soil moisture content at each location for a TranA and b TranB. Vertical bars correspond to $\mathrm{v} \pm 1$ standard deviation of the relative difference $(\%)$ over time. The blue lines indicate the index of time stability (ITS), and the representative sampling locations (RSLs) with the lowest ITSs are marked in red

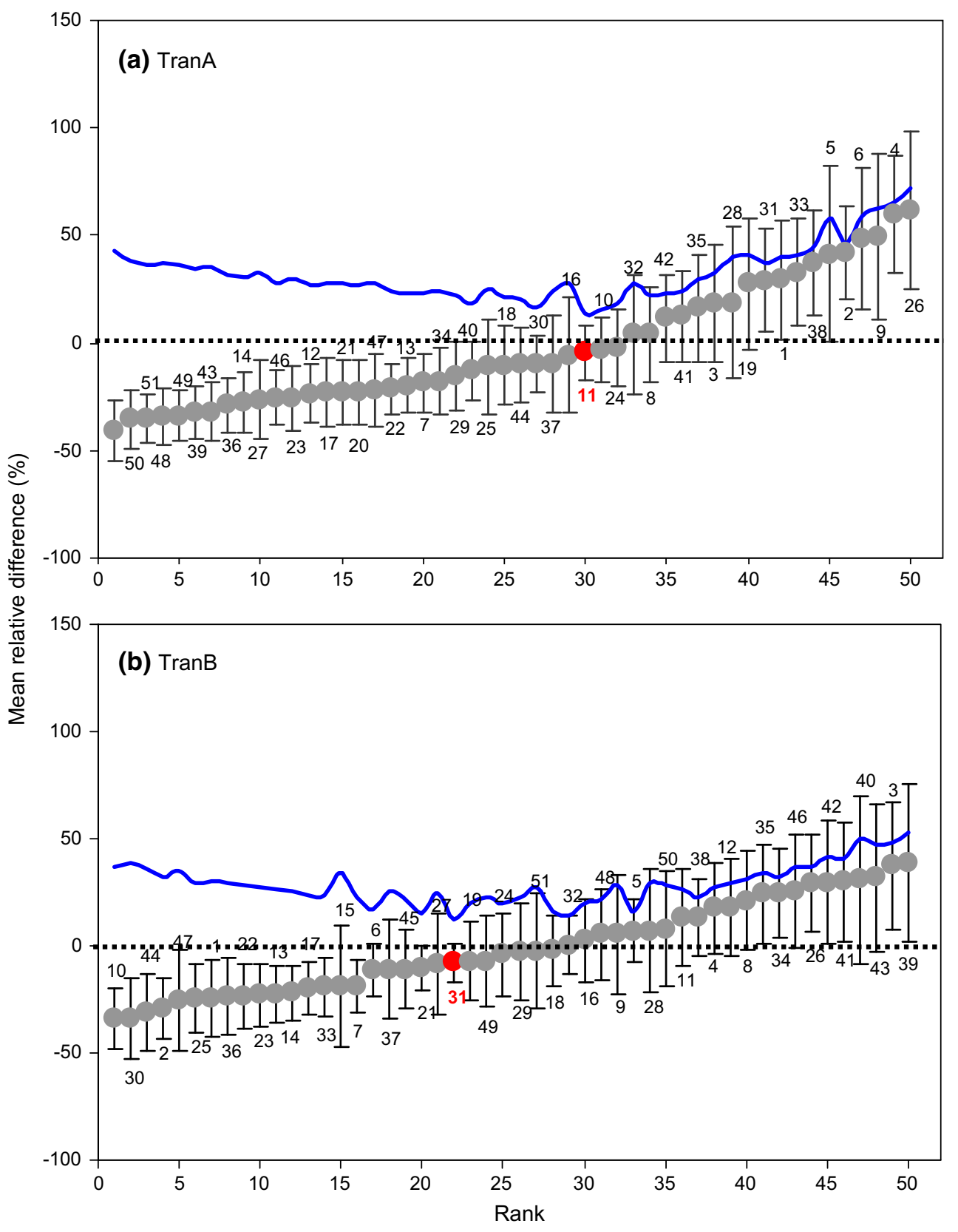

accurate estimates, with values of $R^{2}$ higher than 0.95 and RMSEs lower than $1 \% \mathrm{vol} / \mathrm{vol}$. These results imply that a single sampling location can be identified that accurately estimates the mean moisture content at the scale of a $5-\mathrm{km}$ transect.

\section{Temporal stability of soil moisture during wet and dry periods}

We indicated in the previous section that soil moisture was more temporally stable at dry locations. To further analyse the dependency of temporal stability of soil moisture on soil wetness, we grouped and computed the MRDs, SDRDs, and ITSs separately for dry and wet sampling periods (Table 2). The temporal stability was generally quite sensitive to soil wetness. Wet periods had significant larger ranges of MRDs than did dry periods (Table 2; Fig. 6), which confirmed the findings of "Temporal and spatial analysis of soil moisture" section that spatial variability of soil moisture increased with soil wetness. The higher spatial homogeneity (small range of MRDs) also implied a higher temporal stability, as indicated by the lower SDRD values during the dry period (Table 2; Fig. 6). Moreover, for both dry and wet periods, we detected a 


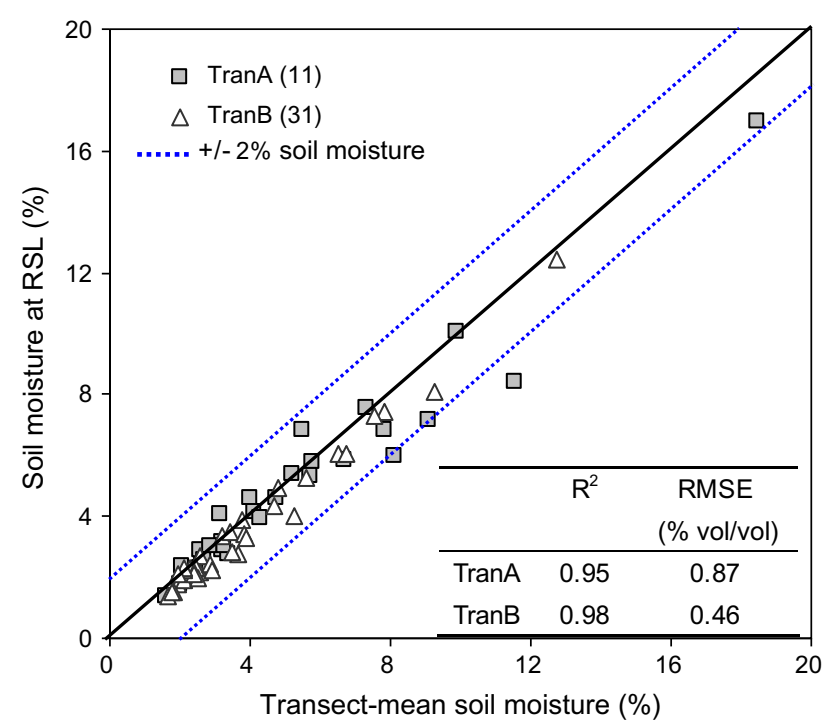

Fig. 5 Soil moisture contents observed at the representative sampling locations (RSLs, in parentheses) versus the mean soil moistures for the two transects during the entire experimental period. The principal regression statistics are also shown: $R^{2}$, coefficient of determination and RMSE, root mean square error

Table 2 Statistical summary of the mean relative difference (MRD), standard deviation of relative difference (SDRD), and index of time stability (ITS) in soil moisture content during wet and dry periods for TranA and TranB

\begin{tabular}{|c|c|c|c|c|}
\hline \multirow[t]{2}{*}{ Parameters } & \multicolumn{2}{|l|}{ TranA } & \multicolumn{2}{|l|}{ TranB } \\
\hline & Wet period & Dry period & Wet period & Dry period \\
\hline \multicolumn{5}{|l|}{ MRD (\%) } \\
\hline Min. & -48.1 & -31.6 & -43.4 & -27.3 \\
\hline Max. & 71.6 & 60.8 & 46.5 & 30.0 \\
\hline Range & 119.7 & 92.4 & 89.9 & 57.3 \\
\hline \multicolumn{5}{|l|}{ SDRD $(\%)$} \\
\hline Mean & 21.2 & $15.1 * *$ & 19.3 & $16.1 *$ \\
\hline Min. & 10.1 & 7.1 & 7.9 & 7.0 \\
\hline Max. & 41.8 & 30.0 & 40.5 & 41.4 \\
\hline Range & 31.7 & 22.9 & 32.6 & 34.4 \\
\hline \multicolumn{5}{|l|}{ ITS (\%) } \\
\hline Mean & 39.1 & $27.2 * *$ & 32.9 & $22.4 * *$ \\
\hline Min. & 15.9 & 9.5 & 12.2 & 9.1 \\
\hline Max. & 81.5 & 62.7 & 60.8 & 46.5 \\
\hline Range & 65.6 & 53.2 & 48.6 & 37.4 \\
\hline
\end{tabular}

* and ** indicate statistical significance between wet and dry periods at $p<0.05$ and $p<0.01$, respectively

consistent tendency of high temporal stabilities at the dry locations (Fig. 6). These results suggest that the spatial patterns of soil moisture are more temporally stable during dry periods and that the high temporal stability at dry locations may persist under different conditions of soil moisture. High temporal stabilities during dry periods were also observed by Martínez-Fernández and Ceballos (2003) and Penna et al. (2013). This association, though, cannot be considered as a general relationship, since different results have been reported in several other studies, e.g. a higher temporal stability during wet periods (Gómez-Plaza et al. 2000; Hupet and Vanclooster 2002; Williams et al. 2009; Zhao et al. 2010, 2013) and similar temporal stabilities independent of wetness (Brocca et al. 2010). The different soil properties and the special climatic conditions in this study area may account for the discrepancies. Because of the deep water table in this area, rain is the main source of soil moisture. The soil wets easily when it rains, and soil moisture increases rapidly. However, intensive surface evaporation and infiltration to the sublayer quickly become the significant forces for the distribution of soil moisture after a rain, due to the high evaporation rates and the coarse soil texture in this area. The soil is thus in continuous cycles of drying and recharging and is less temporally stable. According to Martínez-Fernández and Ceballos (2003), the phases of water recharge in soils play a more important role in the instability of soil moisture during wet periods, because the differences in soil texture and hydraulic properties among the locations can enable soils to respond differently to rain and can therefore induce greater variability. On the other hand, the atmospheric factors participating in evaporation (which are quite homogeneous along the transects) during the drying phases are more important than the physical characteristics of the soils in their patterns of soil moisture. In addition, the differences of SDRDs between dry and wet periods were much larger for TranA than for TranB (Table 2), indicating that the characteristics of temporal stability of soil moisture is more susceptible to soil wetness for the fine-textured soil than for the coarse-textured soil.

The previous findings imply that sampling locations exhibiting temporal persistence during wet periods may lose their characteristics of temporal stability when soils dry (Schneider et al. 2008; Zhao et al. 2013). For example, we observed that different moisture conditions led to different ranks of locations, which suggested distinct RSLs (Fig. 6). The RSLs during wet and dry periods were locations 11 and 18 for TranA and locations 31 and 28 for TranB, respectively. Grayson and Western (1998) suggested that the RSLs should be located in 'aspect neutral' parts of a field, i.e. locations where the related factors have average characteristics of the field being considered. As shown in Table 3, the properties at the RLs identified from dry period were close to the transect mean values (Table 1). We can thus use the means of these feasible and simple properties as aids to identify a priori sampling locations during the dry period. The RSLs identified from wet period, however, showed different properties. The 


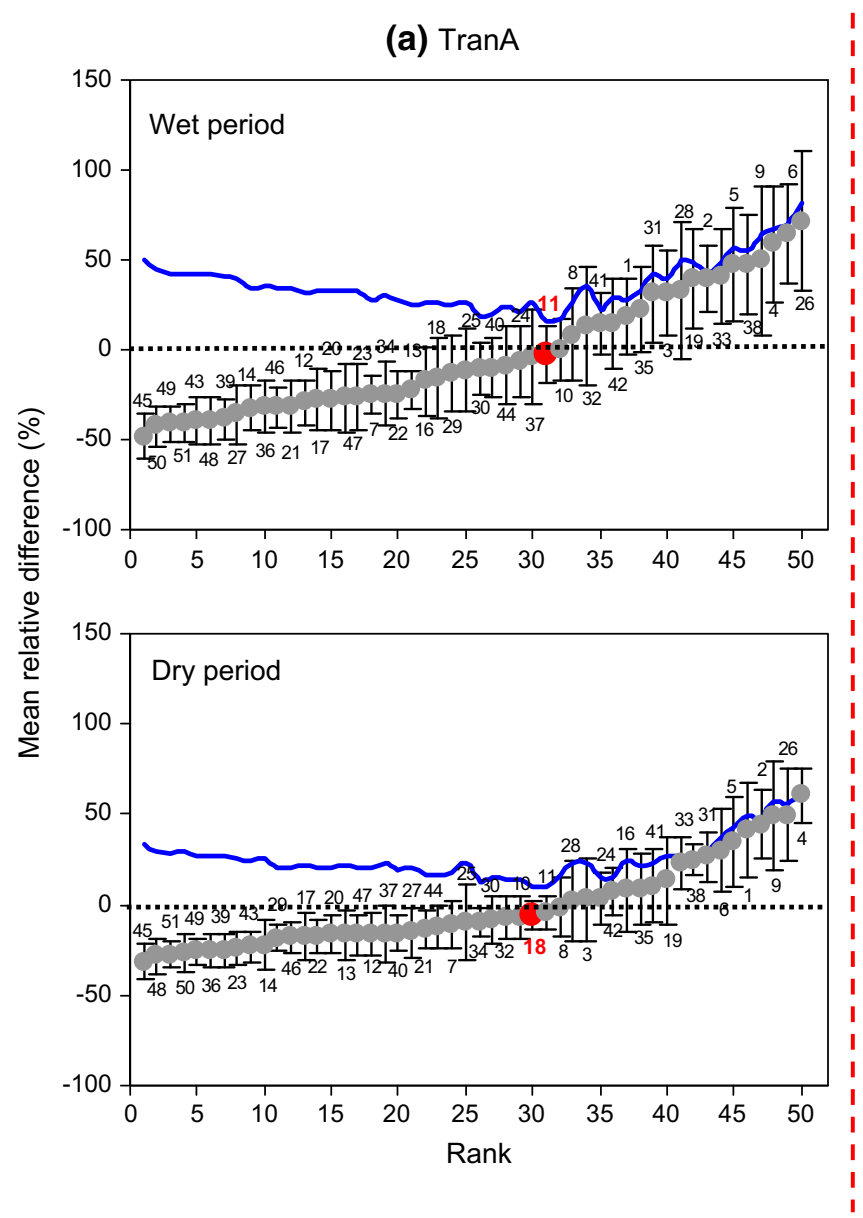

Fig. 6 Rank ordered mean relative difference (\%) of soil moisture content at each location during wet and dry periods for a TranA and b TranB. Vertical bars correspond to \pm 1 standard deviation of the

Table 3 Soil properties at the representative locations identified from wet and dry periods for TranA and TranB

\begin{tabular}{lccccc}
\hline Variables & TranA & & & TranB \\
\cline { 2 - 3 } \cline { 6 - 6 } \cline { 6 - 6 } & 11 (wet) & 18 (dry) & & 31 (wet) & 28 (dry) \\
\hline Sand $(\%)$ & 79.4 & 70.6 & & 96.5 & 86.2 \\
Silt $(\%)$ & 8.4 & 14.0 & & 1.6 & 7.1 \\
Clay $(\%)$ & 12.2 & 15.4 & & 1.9 & 6.8 \\
BD $\left(\mathrm{g} / \mathrm{cm}^{-3}\right)$ & 1.6 & 1.4 & & 1.7 & 1.7 \\
Ks $\left(10^{-5} \mathrm{~m} / \mathrm{s}\right)$ & 0.3 & 0.2 & & 0.3 & 0.7 \\
TP $(\%)$ & 37.9 & 47.2 & & 27.7 & 33.0 \\
SOC $(\mathrm{g} / \mathrm{kg})$ & 1.4 & 1.9 & & 1.1 & 1.5 \\
\hline
\end{tabular}

locations with a relatively coarser texture produced more temporally stable characteristics (Table 3 ). This can be attributed to the inability of these soils to retain water that (b) $\operatorname{TranB}$

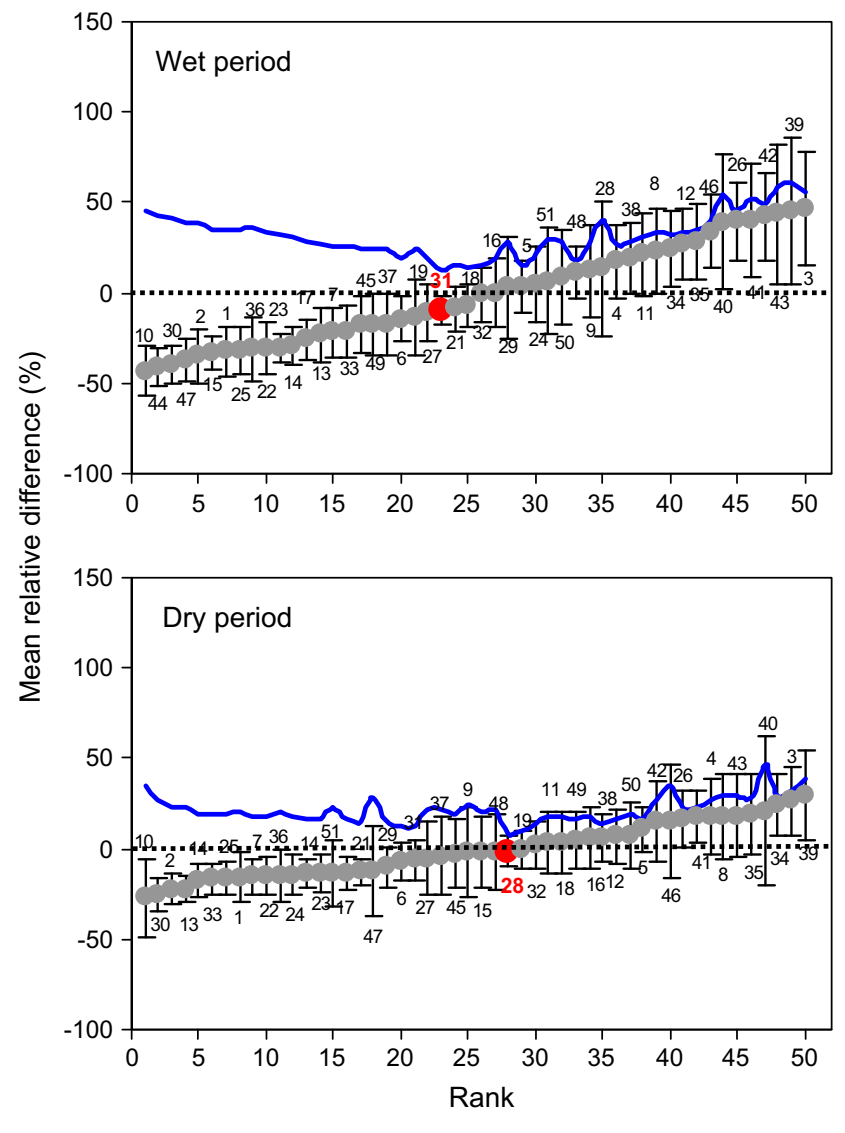

relative difference (\%) over time. The blue lines indicate the index of time stability (ITS), and the representative sampling locations (RSLs) with the lowest ITSs are marked in red

decrease the temporal variability caused by the rains during the wet period.

Although the characteristics of temporal stability at some locations varied between conditions of soil wetness, the RSLs identified from wet/dry periods were still able to accurately estimate the mean moisture contents of the transects for the entire sampling period, with $R^{2}$ ranging from 0.88 to 0.95 and RMSE ranging from 0.46 to 1.38 (Table 4). Notably, the estimates tended to be better for TranB than for TranA regardless of soil wetness, which implies that using RSLs to represent the mean soil moistures of the transects is more reliable for regions with coarse-textured soil. The RSLs identified during wet periods produced much better estimates of the transect mean moistures for the entire period than did those identified during dry periods. Also, careful observation indicated that the RSLs identified during wet periods were quite consistent with those identified for the entire study period 
Table 4 Coefficients of determination $\left(R^{2}\right)$ and root mean square errors (RMSEs) derived from the linear regression of measured soil moisture content and estimates from the representative sampling locations (RSLs) during wet and dry periods for TranA and TranB

\begin{tabular}{|c|c|c|c|c|c|c|}
\hline & \multicolumn{3}{|c|}{ TranA } & \multicolumn{3}{|c|}{ TranB } \\
\hline & RSL & $R^{2}$ & $\operatorname{RMSE}(\% \mathrm{vol} / \mathrm{vol})$ & RSL & $R^{2}$ & RMSE (\% vol/vol) \\
\hline Wet period & 11 & 0.95 & 0.87 & 31 & 0.98 & 0.46 \\
\hline Dry period & 18 & 0.88 & 1.38 & 28 & 0.90 & 1.04 \\
\hline
\end{tabular}

(Figs. 4, 6). All these results indicate that the dynamics of soil moisture during wet periods play an important role in determining the characteristics of temporal stability for a long-term simulation of soil moisture.

\section{Effect of sampling frequency on the determination of temporal stability}

To evaluate the effect of sampling frequency on the characteristics of temporal stability, the data were sequentially reduced. The data obtained at time intervals of 2,3 , and 4 weeks were separately selected and analysed for relative differences and were then compared with the results for the entire study period, as shown in Table 5. The minimum, maximum, and ranges of MRD generally did not change with a decrease in sampling frequency (i.e. an increase in sampling interval), but the ranking of the sampled locations changed substantially (Figs. 4,7). These results are related to the very similar values of MRD at the different locations, which indicates that small changes of MRD may be associated with considerable variation in rank. The temporal stability of soil moisture as indicated by SDRD also changed with a reduction in sampling frequency. Paired-samples $t$ tests showed that the SDRDs for the three reduced sampling frequencies for TranA were significantly lower than the SDRD for the entire study period $(p<0.01)$ (Table 5), indicating better estimates of temporal stability of soil moisture. As previously indicated, the temporal variations of soil moisture in this region occur mainly during wet periods and are caused by rain, but because the rainfall in this region is highly variable over time, a low sampling frequency decreases the probability of detecting all temporal variations due to rain and thus leads to high estimates of temporal persistence of soil moisture. Because rain did not substantially affect the temporal stability of soil moisture in the coarse-textured soil, as shown in the previous section, sampling frequency had no effect on the temporal stability of soil moisture for TranB $(p>0.05)$ (Table 5).

Table 5 Statistical summary of the mean relative difference (MRD), standard deviation of relative difference (SDRD), and index of time stability (ITS) in soil moisture content with different sampling intervals (frequencies) for TranA and TranB

\begin{tabular}{|c|c|c|c|c|c|c|c|c|}
\hline \multirow[t]{2}{*}{ Parameters } & \multicolumn{4}{|l|}{ TranA } & \multicolumn{4}{|l|}{ TranB } \\
\hline & Entire time period & 2 weeks & 3 weeks & 4 weeks & Entire time period & 2 weeks & 3 weeks & 4 weeks \\
\hline \multicolumn{9}{|l|}{ MRD (\%) } \\
\hline Min. & -40.5 & -35.5 & -40.6 & -35.7 & -34.0 & -33.2 & -33.3 & -33.8 \\
\hline Max. & 61.6 & 66.7 & 70.5 & 66.2 & 38.4 & 39.3 & 38.2 & 38.5 \\
\hline Range & 102.2 & 102.2 & 111.1 & 101.9 & 72.4 & 72.5 & 71.5 & 72.4 \\
\hline \multicolumn{9}{|l|}{ SDRD (\%) } \\
\hline Mean & 21.1 & $18.5^{*}$ & $19.5^{*}$ & $17.6^{*}$ & 20.8 & 21.0 & 20.6 & 21.2 \\
\hline Min. & 11.0 & 7.8 & 8.2 & 7.7 & 9.1 & 8.1 & 8.6 & 6.7 \\
\hline Max. & 41.1 & 32.8 & 40.4 & 35.1 & 39.5 & 47.8 & 33.6 & 55.7 \\
\hline Range & 30.1 & 25.0 & 32.2 & 27.4 & 30.3 & 39.8 & 25.0 & 49.0 \\
\hline \multicolumn{9}{|l|}{ ITS (\%) } \\
\hline Mean & 34.9 & $31.8^{*}$ & 34.9 & $31.6^{*}$ & 29.5 & 29.3 & 28.4 & 28.7 \\
\hline Min. & 13.3 & 13.8 & 13.2 & 8.4 & 12.1 & 9.1 & 11.0 & 7.2 \\
\hline Max. & 71.8 & 71.3 & 76.8 & 74.4 & 53.1 & 60.2 & 50.1 & 63.1 \\
\hline Range & 58.5 & 57.5 & 63.6 & 66.0 & 41.0 & 51.2 & 39.0 & 55.8 \\
\hline
\end{tabular}

* Indicates statistical significance between the reduced sampling frequency and the entire study period at $p<0.05$ 
(a) $\operatorname{TranA}$
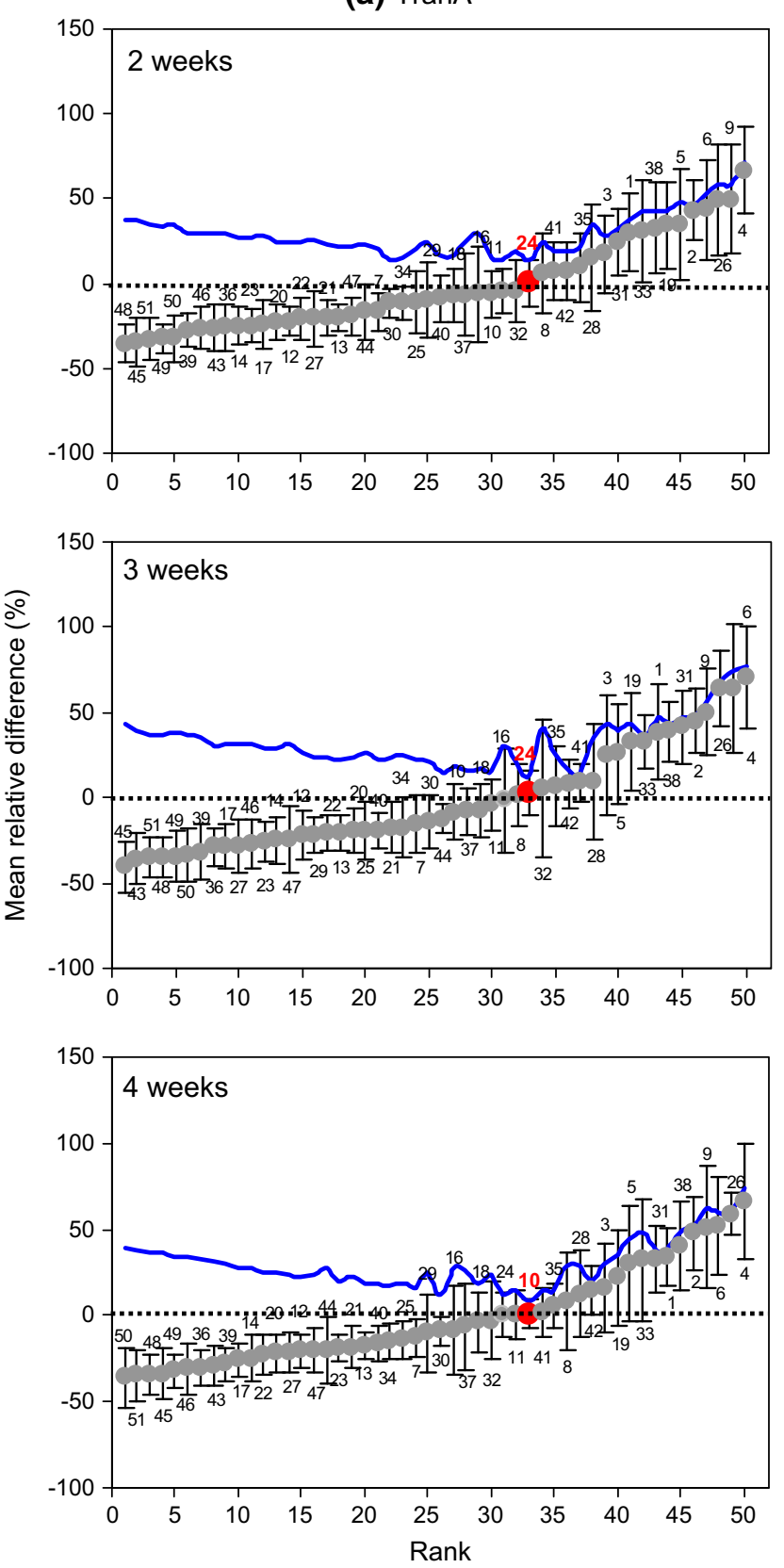

Fig. 7 Rank ordered mean relative difference (\%) of soil moisture content at each location with different sampling intervals (frequencies) for a TranA and b TranB. Vertical bars correspond to \pm 1

As shown in Table 6, the RSLs identified for the sampling intervals of 2, 3, and 4 weeks were locations 24,24 , and 10 and locations 28, 18, and 31 for TranA and TranB, respectively. These results are inconsistent with those reported by Zhao et al. (2013) who observed that the RSLs identified as temporally stable were insensitive to sampling frequency. (b) $\operatorname{TranB}$
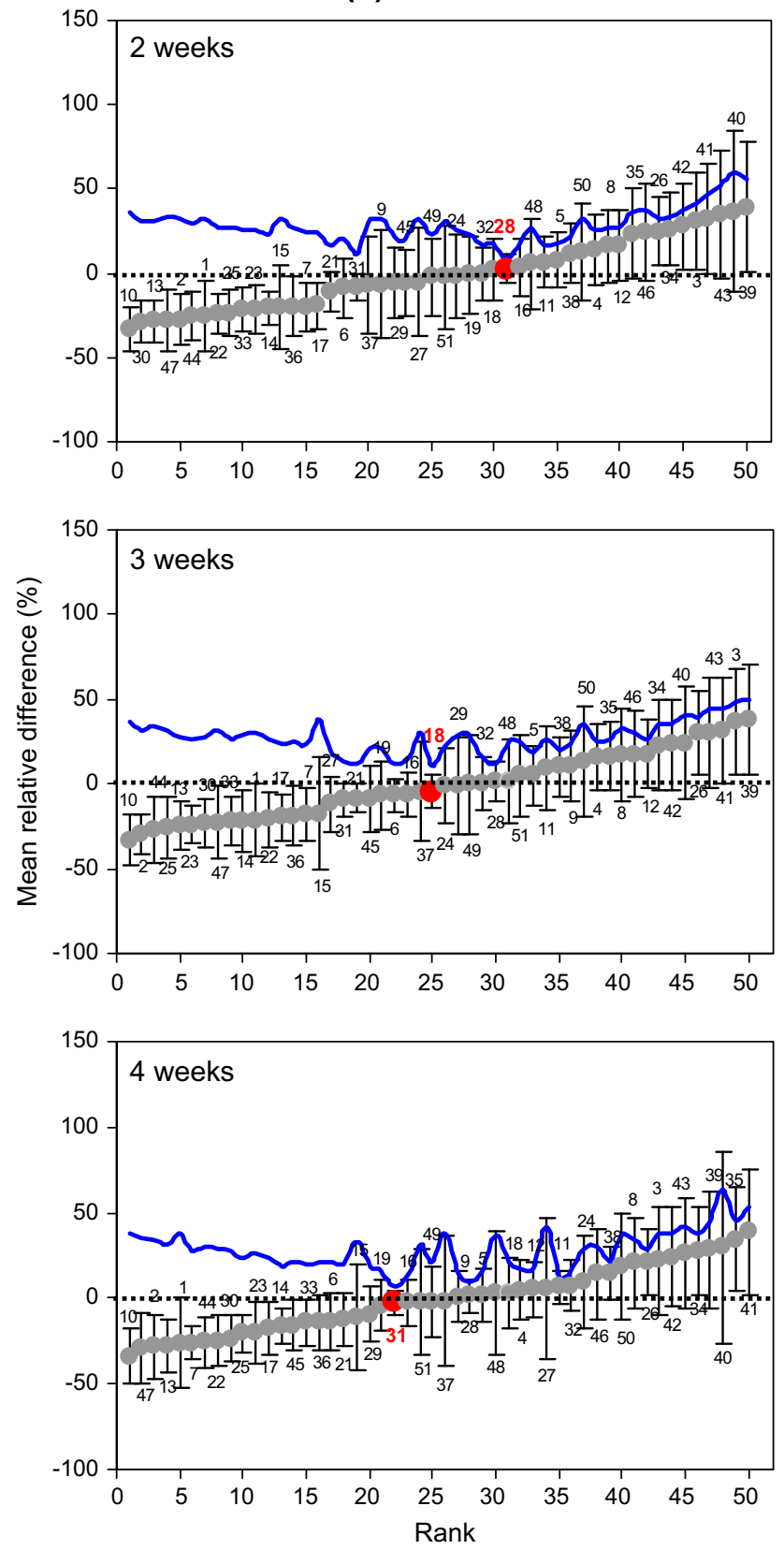

standard deviation of the relative difference (\%) over time. The blue lines indicate the index of time stability (ITS), and the representative sampling locations (RSLs) with the lowest ITSs are marked in red

The soil moistures at our RSLs were also compared with the mean soil moistures of the transects (Table 6). The high values of $R^{2}$ and low RMSEs imply that even though the identified RSLs change with decreasing sampling frequency, they still retain the ability to accurately estimate the mean soil moistures of the transects. 
Table 6 Coefficients of determination $\left(R^{2}\right)$ and root mean square errors (RMSEs) derived from the linear regression of measured soil moisture content and estimates from the representative sampling locations (RSLs) for different sampling intervals for TranA and TranB

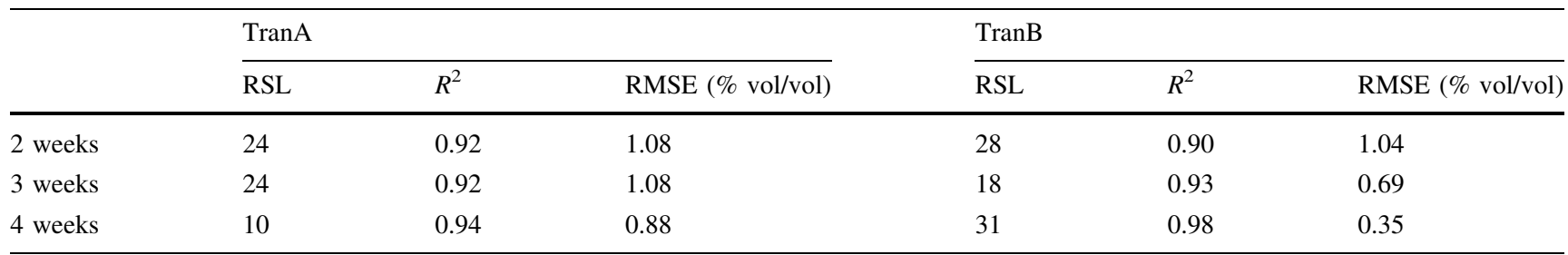

\section{Conclusions}

We investigated the spatial variability and temporal stability of surface soil moisture along two 5-km transects in a desert area. The original time series of the samplings was artificially divided into two time periods (wet and dry periods) that presented different conditions of soil wetness, and lower sampling frequencies were analysed. The main results are summarised as follows:

1. The mean soil moistures of both transects were highly linked to precipitation. TranA, with a finer soil texture, consistently had higher soil moisture contents and variability than did TranB with a coarser soil texture. The spatial variability of soil moisture increased with increasingly wetter soil.

2. Surface soil moisture presented strong temporal stability for both transects, with the relatively homogeneous TranB having a slightly better temporal persistence in the patterns of soil moisture. Dry sampling locations along the transect with relatively higher sand contents tended to have more pronounced temporal stabilities.

3. A single sampling location could be identified to reliably estimate the mean soil moisture content of the transects, with $R^{2}$ higher than 0.95 and RMSE lower than $1 \% \mathrm{vol} / \mathrm{vol}$.

4. The characteristics of temporal stability of soil moisture in terms of both the statistical parameters (i.e. MRD and SDRD) and the RSL for both transects were sensitive to soil wetness. Dry periods generally presented a higher degree of temporal stability than did wet periods. The temporal stability of the finertextured soil was more likely to be influenced by soil wetness.

5. To a certain degree, sampling frequency influenced some temporal stability characteristics of soil moisture, mostly in the finer-textured soil. However, RSLs able to accurately estimate the mean moisture contents of the transects could still be identified when sampling frequency was reduced. This result has the important implication that moderately decreasing the frequency of sampling is feasible for the spatiotemporal monitoring of soil moisture in this desert region, which can lead to considerable reductions in effort and cost.

Acknowledgments This study was financially supported by the Major Program of the National Natural Science Foundation of China (No. 91025018).

\section{References}

Berndtsson R, Nodomi K, Yasuda H, Persson T, Chen H, Jinno K (1996) Soil water and temperature patterns in an arid desert dune sand. J Hydrol 185:221-240

Biswas A, Si BC (2011) Scales and locations of time stability of soil water storage in a hummocky landscape. J Hydrol 408:100-112

Brocca L, Morbidelli R, Melone F, Moramarco T (2007) Soil moisture spatial variability in experimental areas of Central Italy. J Hydrol 333:356-373

Brocca L, Melone F, Moramarco T, Morbidelli R (2009) Soil moisture temporal stability over experimental areas in Central Italy. Geoderma 148:364-374

Brocca L, Melone F, Moramarco T, Morbidelli R (2010) Spatialtemporal variability of soil moisture and its estimation across scales. Water Resour Res 46:W02516

Brocca L, Tullo T, Melone F, Moramarco T, Morbdelli R (2012) Catchment scale soil moisture spatial-temporal variability. J Hydrol 422:63-75

Choi M, Jacobs JM (2007) Soil moisture variability of root zone profiles within SMEX02 remote sensing footprints. Adv Water Resour 30:883-896

Comegna V, Basile A (1994) Temporal stability of spatial patterns of soil water storage in a cultivated Vesuvian soil. Geoderma 62:299-310

Cosh MH, Jackson TJ, Bindlish R, Prueger JH (2004) Watershed scale temporal and spatial stability of soil moisture and its role in validating satellite estimates. Remote Sens Environ 92:427-435

Cosh MH, Jackson TJ, Moran S, Bindlish R (2008) Temporal persistence and stability of surface soil moisture in a semi-arid watershed. Remote Sens Environ 112:304-313

da Silva AP, Nadler A, Kay BD (2001) Factors contributing to temporal stability in spatial patterns of water content in the tillage zone. Soil Tillage Res 58:207-218

Famiglietti JS, Rudnicki JW, Rodell M (1998) Variability in surface moisture content along a hillslope transect: Rattlesnake Hill, Texas. J Hydrol 210:259-281

Gajem YM, Warrick AW, Myers DE (1981) Spatial dependence of physical properties of a typic Torrifluvent Soil. Soil Sci Soc Am 45:709-715 
Gao L, Shao MA (2012a) Temporal stability of shallow soil water content for three adjacent transects on a hillslope. Agric Water Manag 110:41-54

Gao L, Shao MA (2012b) Temporal stability of soil water storage in diverse soil layers. Catena 95:24-32

Gao XD, Wu PT, Zhao XN, Wang JW, Shi YG, Zhang BQ, Tian L, Li HB (2013) Estimation of spatial soil moisture averages in a large gully of the Loess Plateau of China through statistical and modeling solutions. J Hydrol 486:466-478

Gómez-Plaza A, Alvarez-Rogel J, Albaladejo J, Castillo V (2000) Spatial patterns and temporal stability of soil moisture across a range of scales in a semi-arid environment. Hydrol Process 14:1261-1277

Grant L, Seyfried M, McNamara J (2004) Spatial variation and temporal stability of soil water in a snow-dominated, mountain catchment. Hydrol Process 18:3493-3511

Grayson RB, Western AW (1998) Towards areal estimation of soil water content from point measurements: time and space stability of mean response. J Hydrol 207:68-82

Guber AK, Gish TJ, Pachepsky YA, van Genuchten MT, Daughtry CST, Nicholson TJ, Cady RE (2008) Temporal stability in soil water content patterns across agricultural fields. Catena 73:125-133

Heathman GC, Cosh MH, Merwade V, Han E (2012) Multi-scale temporal stability analysis of surface and subsurface soil moisture within the Upper Cedar Creek Watershed, Indiana. Catena 95:91-103

Hills RC, Reynolds SG (1969) Illustrations of soil moisture variability in selected areas and plots of different sizes. J Hydrol 8:27-47

Hu W, Shao MA, Han FP, Reichardt K, Tan J (2010a) Watershed scale temporal stability of soil water content. Geoderma 158:181-198

$\mathrm{Hu}$ W, Shao MA, Reichardt K (2010b) Using a new criterion to identify sites for mean soil water storage evaluation. Soil Sci Soc Am J 74:762-773

Hupet F, Vanclooster M (2002) Intraseasonal dynamics of soil moisture variability within a small agricultural maize cropped field. J Hydrol 261:86-101

Jacobs JM, Mohanty BP, Hsu EC, Miller D (2004) SMEX02: field scale variability, time stability and similarity of soil moisture. Remote Sens Environ 92:436-446

Jia YH, Shao MA (2013) Temporal stability of soil water storage under four types of revegetation on the northern Loess Plateau of China. Agric Water Manag 117:33-42

Jia XX, Shao MA, Wei XX, Wang YQ (2013a) Hillslope scale temporal stability of soil water storage in diverse soil layers. J Hydrol 498:254-264

Jia YH, Shao MA, Jia XX (2013b) Spatial pattern of soil moisture and its temporal stability within profiles on a loessial slope in northwestern China. J Hydrol 495:150-161

Kachanoski RG, Jong E (1988) Scale dependence and the temporal persistence of spatial patterns of soil water storage. Water Resour Res 24:85-91

Kamgar A, Hopmans JW, Wallender WW, Wendroth O (1993) Plotsize and sample number for neutron probe measurements in small field trials. Soil Sci 156:213-224

Lin H (2006) Temporal stability of soil moisture spatial pattern and subsurface preferential flow pathways in the Shale Hills Catchment. Vadose Zone J 5:317-340

Martínez-Fernández J, Ceballos A (2003) Temporal stability of soil moisture in a large-field experiment in Spain. Soil Sci Soc Am J 67:1647-1656
Meyles E, Williams A, Ternan L, Dowd J (2003) Runoff generation in relation to soil moisture patterns in a small Dartmoor catchment, Southwest England. Hydrol Process 17:251-264

Mohanty BP, Skaggs TH (2001) Spatio-temporal evolution and timestable characteristics of soil moisture within remote sensing footprints with varying soil, slope, and vegetation. Adv Water Resour 24:1051-1067

Pan YX, Wang XP, Su YG, Li XJ, Gao YH (2009) Temporal stability of surface soil moisture in artificially revegetated desert area. J Desert Res 29:81-86 (in Chinese)

Penna D, Borga M, Norbiato D, Fontana GD (2009) Hillslope scale soil moisture variability in a steep alpine terrain. J Hydrol 364:311-327

Penna D, Brocca L, Borga M, Dalla Fontana G (2013) Soil moisture temporal stability at different depths on two alpine hillslopes during wet and dry periods. J Hydrol 477:55-71

Peters-Lidard CD, Pan F (2002) Re-thinking the contradictions of soil moisture spatial variability. Eos Trans AGU, 83(47), Fall Meet Suppl, Abstract NG12C-1042

Rodriguez-Iturbe I, D'odorico P, Porporato A, Ridolfi L (1999) On the spatial and temporal links between vegetation, climate, and soil moisture. Water Resour Res 35:3709-3722

Schaap MG, Leij FJ, van Genuchten M (1998) Neural network analysis for hierarchical prediction of soil hydraulic properties. Soil Sci Soc Am 62:847-855

Schneider K, Huisman JA, Breuer L, Zhao Y, Frede HG (2008) Temporal stability of soil moisture in various semi-arid steppe ecosystems and its application in remote sensing. J Hydrol 359:16-29

Vachaud G, Passerat de Silans A, Balabanis P, Vauclin M (1985) Temporal stability of spatially measured soil water probability density function. Soil Sci Soc Am J 49:822-828

Vanderlinden K, Vereecken H, Hardelauf H, Herbst M, Martínez G, Cosh MH, Pachepsky YA (2012) Temporal stability of soil water contents: a review of data and analyses. Vadose Zone J. doi:10. 2136/vzj2011.0178

Vivoni ER, Gebremichael M, Watts CJ, Bindlish R, Jackson TJ (2008) Comparison of ground-based and remotely-sensed surface soil moisture estimates over complex terrain during SMEX04. Remote Sens Environ 112:314-325

Western AW, Blöschl G (1999) On the spatial scaling of soil moisture. J Hydrol 217:203-224

Western AW, Grayson RB, Blöschl G, Willgoose GR, McMahon TA (1999) Observed spatial organization of soil moisture and its relation to terrain indices. Water Resour Res 35:797-810

Williams CJ, McNamara JP, Chandler DG (2009) Controls on the temporal and spatial variability of soil moisture in a mountainous landscape: the signature of snow and complex terrain. Hydrol Earth Syst Sci Dis 13:1325-1336

Zhao Y, Peth S, Wang XY, Lin H, Horn R (2010) Controls of surface soil moisture spatial patterns and their temporal stability in a semi-arid steppe. Hydrol Process 24:2507-2519

Zhao L, Yang K, Qin J, Chen YY, Tang WJ, Montzka C, Wu H, Lin CG, Han ML, Vereecken H (2013) Spatiotemporal analysis of soil moisture observations within a Tibetan mesoscale area and its implication to regional soil moisture measurements. J Hydrol 482:92-104 